\title{
POLYMERIC PHARMACEUTICAL FORMS - THE FORMS OF THE FUTURE
}

\author{
Tatyana Hristova ${ }^{1}$, Rumyana Cherkezova ${ }^{1}$, Neli Koseva ${ }^{2}$, Violeta Mitova ${ }^{2}$, Kolio Troev $^{2}$ \\ ${ }^{1}$ Department of Medical and Biological Sciences, Medical University of Varna \\ ${ }^{2}$ Institute of Polymers, Bulgarian Academy of Sciences - Sofia
}

\begin{abstract}
Polymers are gaining even more ground as carriers of therapeutic agents because of the potential to modify the properties of clinically proven medicines, which have limited use due to their shortcomings and side effects. Polymeric pharmaceutical systems are able to solve problems such as dose limitation of drug, poor water-solubility and duration of drug action. Polymer-pharmaceutical conjugates enable the improvement of drug localization in target tissue and also to optimize the drug release speed. Of great interest is the development of even cleverer and newer pharmaceutical forms made of polymers of varied reactivity, which allows for their binding with different biologically active substances.
\end{abstract}

Keywords: polymeric pharmaceutical forms, polymer carrier, polymer, polyphosphoesters

\section{INTRODUCTION}

Antitumor agents used in treating cancer cause a great number of toxic side effects (1). They result in decreasing the dose of the chemotherapeutic agent and also in therapy discontinuation. Therefore, it is clinically important to create new effective agents, the function of which is to stop the growth of tumor cells and to limit the toxic effects. A promising strategy developed to that end is the implementation of polymeric pharmaceutical systems $(2,3)$. These systems have been developed to provide: 1) drugs that attack tumor cells; 2) local delivery and maintenance of drug therapeutic concentration in the target tis-

\footnotetext{
Address for correspondence:

Tatyana Hristova

Department of Medical and Biological Sciences,

Faculty of Dental Medicine, Medical University of Varna

84 Tzar Osvoboditel str.

9000 Varna, Bulgaria

e-mail: Tatiana.Hristova@mu-varna.bg
}

Received: November 10, 2015

Accepted: December 1, 2015 sue for a longer period; 3) reduction of systemic side effects.

\section{ADVANTAGES OF POLYMERIC PHARMACEUTICAL SYSTEMS}

Drug delivery systems are used by millions of patients for the treatment of different diseases. The use of such systems have led to the formation of new or the improvement of already existing therapies. A strategy to suppress the toxicity of drug substances involves their binding with polymers (4-11). The idea of covalent binding of a low molecular weight drug to a hydrophilic polymer carrier in order to increase its therapeutic effect was suggested by Helmut Ringsdorf (4) in 1975 for the first time. This model not only provides for a change in the pharmacokinetics of the bound drug but also enables the attack of the target tissue by introduction of a guiding residue to the same polymer carrier. A large number of preclinical trials were conducted in the 80 s and the early 90 s of the $20^{\text {th }}$ century with the objective to optimize the characteristics and prove the safety of polymer carriers and polymer-pharmaceutical linkers (12-14). A few technologies influence cancer in ways 
that drug delivery systems do. The latter enable treatment of cancer with significantly decreased side effects and provide for new and better chemotherapeutic regimes based on existing pharmaceuticals (3).

The possibility for anticancer drugs to be delivered locally raises the prospect of improving the safety and efficacy of chemotherapy. The medicine becomes more effective if put next or directly to the target tissue, whereby much higher local concentration could be achieved (3). One major benefit of polymeric pharmaceutical systems is the possibility to attack target tissues by delivering the therapeutic agent right to a specific location or organ within the body. Polymer conjugates are nanosized multicomponent systems developed following clinical studies of antitumor substances. They are both applicable as independent and combined agents. Polymer properties determine the circulation time and cellular absorption speed, decreasing the toxicity of effective cytotoxic drugs and imparting favorable physicochemical properties (e.g. increase in the solubility of lipophilic drugs). Unlike most low molecular weight substances that are prone to systematic distribution and fast release in the blood flow, high molecular weight compounds, due to their size, demonstrate prolonged circulation. Since polymers lack the capacity to penetrate through cell membranes and to overcome different biological barriers, their distribution in human body is limited (15). As a result, the pharmacokinetics of bound drug is entirely changed, and at the same time its ability to react with substrates and receptors is preserved. Immobilized drugs are with lower toxicity and completely delayed activity as compared to low molecular weight drugs.

Despite the significant progress in chemotherapeutics delivery achieved so far, there are a number of outstanding problems. In the case of local delivery, there is limited drug diffusion within cancer tissues and sometimes unwanted drug and polymer carrier interactions (3). It is therefore necessary to continue the development of drug delivery systems that would allow for improvement and widening of therapeutic instrumentation in the fight against a wide range of tumors.

The use of polymer-pharmaceutical conjugates customarily covers the delivery of independent therapeutic agents but multivalence of polymer carriers allows for their application also for drug delivery in various combinations. It is an outstanding therapeutic option, as it is getting more and more clear that multiagent therapy is preferred to monoagent therapy in treatment and prevention of diseases such as cancer (16). Currently, only a few study groups suggest the use of polymer carriers for the delivery of combined drugs (17-19). Increasing number of watersoluble polymers are used as macromolecular partners for binding low molecular weight drugs.

\section{APPLICATION OF POLYMERS AS CARRIERS OF BIOLOGICALLY AC- TIVE SUBSTANCES}

In order to be selected as a carrier of drug substance, a polymer should meet a number of requirements: biocompatibility, non-immunogenicity, nontoxicity, biodegradability or a suitable molecular mass - conformed to the renal permeability, presence of suitable reactive functional groups for binding with the given drug. An important parameter of polymer-pharmaceutical conjugates is the drug release from the polymer carrier. A wide range of polymers have wide application, such as polyethylene glycols $(1,15,20-32)$, polyesters (33), polyether-polyesters (34), peptides $(35,36)$, polyglutamic acid $(37,38)$, hyaluronic acid (39-41), polyphosphoesters $(32,42,43)$.

An important class of phosphorus-containing polymers are poly(alkylene H-phosphonate)s due to their diverse reaction mechanism, which enables introduction of different functional groups and binding with biologically active agents. Over the last years, there is a substantial increase in the number of scientific publications related to the synthesis and application of polyphosphoesters as carriers of biologically active agents, including the radioprotectors 2-aminoethantiol (44) and WR2721 (45); the multifunctional alkylating agent bendamustine (46); AZT, the effective drug for treatment of HIV (47).

The development of amphiphilic copolymers applicable for physical immobilization of hydrophobic drugs has generated a great interest. Non-covalent interactions underlie numerous natural processes. One of the most important driving forces in forming biomacromolecule associates is the formation of a hydrogen bond, which also plays a significant role in the association of synthetic polymers. In water solutions, proton acceptor poly- 
mers could be associated with proton donor polymers (48). Promising carriers for physical immobilization (by means of hydrogen bonds) are polyphosphoesters $(46,49,50)$. Poly(hydroxyoxyethylene phosphate)s are biodegradable, biocompatible, water-soluble and low-toxic polymers (15). Chemotherapeutic agents with phosphate structures would interact preferentially with tumor cells (51). Moreover, dephosphorylation often takes place more easily in tumor cells compared to normal cells (52). Studies performed on experimental animals demonstrate that the polymer poly(hydroxyoxyethylene phosphate) does not show toxic effects after intravenous injection with a dose of $1000 \mathrm{mg} / \mathrm{kg}$ body weight. Synthesized polymer pharmaceutical formulations based on poly(hydroxyoxyethylene phosphate) and the low molecular weight drug paclitaxel show 4000 times higher solubility of the drug. The results of biostudies with a polymer complex of paclitaxel performed on experimental animals showed decrease of the antitumor drug characteristic effect of body weight reduction. Such results lead to the conclusion that poly(hydroxyoxyethylene phosphate)s could be successfully considered as multifunctional carriers of drug substances (53).

\section{CONCLUSION}

Modern medicine is facing the challenge of deriving maximum therapeutic benefit in the development of new strategies for treating different kinds of tumors. The optimism that we could expect even more complex polymers as a new and significant supplement to cancer control approaches used so far is entirely justified. The achievements made as a result of numerous studies (improved water-solubility of lipophilic drugs and considerably decreased toxic side effects) give grounds for future development of polymeric pharmaceutical forms in order to improve the treatment quality and efficacy for millions of patients.

\section{REFERENCES}

1. Lee KH, Chung YJ, Kim YC, Song SJ. Anti-tumor activity of paclitaxel prodrug conjugated with polyethylene glycol. Bull. Korean Chem. Soc. 2005;26(7):1079-82.
2. Huang PS, Oliff A. Drug-targeting strategies in cancer therapy. A Curr Opin Genet Dev. 2001;11(1):104-10.

3. Moses MA, Brem H, Langer R, Advancing the field of drug delivery: Taking aim at cancer. Cancer Cell. 2003;4:337-41.

4. Ringsdorf H. Structure and properties of pharmacologically active polymers. J Polym Sci Polym Symp. 1975;51(1):135-53.

5. Ottenbrite RM, Regelson W, Kaplan A, Carchman R, Morahan P, Munson A. In Polymer Drugs ( Donaruma \& Vogl, Eds.). New York: Academic Press; 1978.

6. Uhrich K. Trends in Polymer Science. 1997;5:388.

7. Duncan R. Drug-polymer conjugates: potential for improved chemotherapy. Anti-Cancer Drug. 1992;3:175-210.

8. Senter PD, Svensson HP, Schreiber GJ, Rodriguez JL, Vrudhula VM. Poly(ethylene glycol)-

Doxorubicin conjugates containing beta-lactamasesensitive linkers. Bioconjugate Chem. 1995; 6(4):389-94.

9. Schacht EH. Ionic polymers as drug carriers. In: Brucks (ed) Controlled Drug Delivery. CRC, Boca Raton. 1983; Chapter 6, vol 1. p.149

10. De Duve C, De Barsy T, Poole B, Trouet A, Tulkens P, Van Hoof F. Lysosomotropic agents. Biochem Pharmacol. 1974;23(18):2495-531.

11. Greco F, Vincent MJ. Polymer-drug conjugates: current status and future trends. Frontiers Biosci. 2008;13:2744-56.

12. Duncan R, Lloyd JB, Kopecek J. Degradation of side chains of N-(2 hydroxypropyl) methacrylamide copolymers by lysosomal enzymes. Biochem Biophys Res Commun. 1980;94:284-90.

13. Duncan R, Cable HC, Lloyd JB, Rejmanova P, Kopecek J. Polymers containing enzymatically degradable bonds, 7. Design of oligopeptide sidechains in poly[ $N$-(2-hydroxypropyl)methacrylamide] copolymers to promote efficient degradation by lysosomal enzymes. Makromol Chem. 1983;184(10):1997-2008.

14. Duncan R, Seymour LW, O’Hare KB, Wedge S, Hume IC, Ulbrich K, et.al. Preclinical evaluation of polymer-bound doxorubicin. J Control Rel. 1992;19:331-46.

15. Troev K.D. Polyphosphoesters: Chemistry and Application. Amsterdam, NY: Elsevier; 2012. 
Tatyana Hristova, Rumyana Cherkezova, Neli Koseva et al.

16. Gee JMW, Howell A, Gullick WJ, Benz CC, Sutherland RL, Santen RJ, et.al. Growth factor signalling, resistance and breast cancer. Endocr Relat Cancer. 2005;12:S1-S7.

17. Vicent MJ, Greco F, Nicholson RI, Paul A, Griffiths PC, Duncan R. Polymer therapeutics designed for a combination therapy of hormonedependent cancer. Angew Chem Int Ed Engl. 2005;44:4061-6.

18. Vasey PA, Kaye SB, Morrison R, Twelves C, Wilson P, Duncan R, et.al. Phase I clinical and pharmacokinetic study of PK1 [N-(2-hydroxypropyl)methacrylamide copolymer doxorubicin]: first member of a new class of chemotherapeutic agents-drugpolymer conjugates. Clin. Cancer Res. 1999;5(1): 83-94.

19. Greco F, Vicent MJ, Gee S, Jones AT, Gee J, Nicholson RI, et al. Investigating the mechanism of enhanced cytotoxicity of HPMA copolymerDox-AGM in breast cancer cells. J Contr Rel. 2007;117(1):28-39.

20. Greenwald RB, Pendri A, Conover C, Gilbert C, Yang R, Xia J. Drug delivery systems. 2. Camptothecin 20-O-poly(ethylene glycol) ester transport forms. J Med Chem. 1996;39(10):1938-40.

21. Conover CD, Pendri A, Lee C, Gilbert CW, Shum KL, Greenwald RB. Camptothecin delivery systems: the antitumor activity of a camptothecin20-0-polyethylene glycol ester transport form. Anticancer Res. 1997;17:3361-8.

22. Greenwald RB, Pendri A, Conover CD, Lee C, Choe YH, Gilbert C, et al. Camptothecin20-PEG ester transport forms: the effect of spacer groups on antitumor activity. Biorg Med Chem. 1998;6(5):551-62.

23. Greenwald RB, Gilbert CW, Pendri A, Conover CD, Xia J, Martinez A. Drug delivery systems: water soluble taxol 2'-poly(ethylene glycol) ester prodrugs-design and in vivo effectiveness. J Med Chem. 1996;39(2):424-31.

24. Li C, Yu D, Inoue T, Yang DJ, Milas L, Hunter NR, et al. Synthesis and evaluation of water-soluble polyethylene glycol-paclitaxel conjugate as a paclitaxel prodrug. Anticancer Drug. 1996;7(6):642-8.

25. Nathan A, Zalipsky S, Ertel SI, Agathas SN, Yarmush ML, Kohn J. Copolymers of lysine and polyethylene glycol: a new family of functionalized drug carriers. Bioconjugate Chem. 1993;4(1):54-62.
26. Greenwald RB, Pendri A, Bolikal D, Gilbert C. Highly water soluble taxol derivatives: 2 '-polyethyleneglycol esters as potential prodrugs. Bioorg Med Chem Lett. 1994;4(20):2465-70.

27. Greenwald RB, Pendri A, Bolikal D. Highly water soluble taxol derivatives: 7-polyethylene glycol carbamates and carbonates. J Org Chem.1995;60(2):331-36.

28. Ryu BY, Sohn JS, Hess M, Choi SK, Choi JK, Jo BW. Synthesis and anti-cancer efficacy of rapid hydrolysed water-soluble paclitaxel pro-drugs. J Biomater Sci Polym. Ed. 2008;19(3):311-24.

29. Feng X, Yuan YJ, Wu JC. Synthesis and evaluation of water-soluble paclitaxel prodrugs. Bioorg. Med Chem Lett. 2002;12(22):3301-3.

30. Zhang X, Li Y, Chen X, Wang X, Xu X, Liang Q, et al. Synthesis and characterization of the paclitaxel/ MPEG-PLA block copolymer conjugate. Biomaterial. 2005;26:2121-8.

31. Xie Z, Lu T, Chen X, Lu C, Zheng Y, Jing X. Triblock poly(lactic acid)-b-poly (ethylene glycol)-bpoly(lactic acid)/paclitaxel conjugates: Synthesis, micellization, and cytotoxicity. J Appl Polym Sci. 2007;105(4):2271-9.

32. Zhang S, Zou J, Elsabahy M, Karwa A, Li A, Moore DA, et al. Poly(ethylene oxide)-block-polyphosphester-based Paclitaxel Conjugates as a Platform for Ultra-high Paclitaxel-loaded Multifunctional Nanoparticles. Chem Sci. 2013;4(5):2122-6.

33. Li G, Liu J, Pang Y, Wang R, Mao L, Yan D, et al. Polymeric micelles with water-insoluble drug as hydrophobic moiety for drug delivery. Biomacromolecules. 2011;12(6):2016-26.

34. Belcheva N, Smid J, Lambov N, Danchev N, Peikov P, Zlatkov A, Tsvetanov C. Polymeric sustained release formulations of the bronchial dilator Vephylline. J Control Release. 1995;37:43-8.

35. Chen X, Plasencia C, Hou Y, Neamati N. Synthesis and biological evaluation of dimeric RGD peptide-paclitaxel conjugate as a model for integrin-targeted drug delivery. J Med Chem. 2005;48(4):1098-106.

36. Papas S, Akoumianaki T, Kalogiros C, Hadjiarapoglou L, Theodoropoulos PA, Tsikaris V. Synthesis and antitumor activity of peptide-paclitaxel conjugates. J Pept Sci. 2007;13(10):662-71.

37. Li C, Yu DF, Newman RA, Cabral F, Stephens LC, Hunter N, et al. Complete regression of well-established tumors using a novel water-soluble poly(l- 
glutamic acid)-paclitaxel conjugate. Cancer Res. 1998;58(11):2404-9.

38. Lee $Y$. Preparation and characterization of folic acid linked poly(L-glutamate) nanoparticles for cancer targeting. Macromol Res. 2006;14(3):387-93.

39. Leonelli F, La Bella A, Migneco LM, Bettolo RM. Design, synthesis and applications of hyaluronic acid-paclitaxel bioconjugates. Molecules. 2008;13(2):360-78.

40. Luo Y, Prestwich GD. Synthesis and selective cytotoxicity of a hyaluronic acid-antitumor bioconjugate. Bioconjugate Chem.1999;10(5):755-63.

41. Luo Y, Ziebell MR, Prestwich GD. A hyaluronic acid-taxol antitumor bioconjugate targeted to cancer cells. Biomacromol. 2000;1(2):208-18.

42. Zhang $\mathrm{P}, \mathrm{Hu} \mathrm{L}$, Yin Q, Zhang Z, Feng L, Li Y. Transferrin-conjugated polyphosphoester hybrid micelle loading paclitaxel for brain-targeting delivery: Synthesis, preparation and in vivo evaluation. J Control Release. 2012;159(3):429-34.

43. Zhang G, Zhang M, He J, Ni P. Synthesis and characterization of a new multifunctional polymeric prodrug paclitaxel-polyphosphoester-folic acid for targeted drug delivery. Polym Chem. 2013;4:4515-25.

44. Georgieva R, Tsevi R, Kossev K, Kusheva R, Balgjiska $\mathrm{M}$, Petrova $\mathrm{R}$, et al. Immobilization of aminothiols on poly(oxyalkylene phosphates). Formation of poly(oxyethylene phosphates)/cysteamine complexes and their radioprotective efficiency. J Med Chem. 2002;45(26):5797-801.

45. Troev K, Tsacheva I, Koseva N, Georgieva R, Gitsov I. Immobilization of aminothiols on poly(oxyethylene H-phosphonate)s and poly(oxyethylene phosphate)s - An approach to polymeric protective agents for radiotherapy of cancer. J Polym Sci Part A Polym Chem. 2007;45(7):1349-63.

46. Pencheva I, Bogomilova A, Koseva N, Obreshkova D, Troev K. HPLC study on the stability of bendamustine hydrochloride immobilized onto polyphosphoesters. J Pharm Biomed Anal. 2008;48(4):1143-50.

47. Troev KD, Mitova VA, Ivanov IG. On the design of polymeric 5'-O-ester prodrugs of 3 '-azido2',3'-dideoxythymidine (AZT). Tetrahedron Lett. 2010;51(47):6123-25.

48. Staikos G, Sotiropoulou M, Bokias G, Bossard F, Oberdisse J, Baikois E. In: Hydrogen bonded inter- polymer complexes. Formation, structure and applications. (Khutoryanskiy VV, Staikos G, Eds.). Abington, UK: World Scientific Publishing (UK) Ltd c/o Morston Book Services; 2009.

49. Bogomilova A, Höhna M, Günthera M, Herrmanna $A$, Troev K, Wagnera E, et al. A polyphosphoester conjugate of melphalan as antitumoral agent. Eur J Pharm Sci. 2013;50(3-4):410-9.

50. Huang SW, Wang J, Zhang PC, Mao HQ, Zhuo RX, Leong KW. Water-soluble and nonionic polyphosphoester: synthesis, degradation, biocompatibility and enhancement of gene expression in mouse muscle. Biomacromolecules. 2004;5(2):306-11.

51. Dugas H, Penney C. In: Bioorganic chemistry: A chemical approach to enzyme action. (Cantor CR, Ed.). Berlin: Springer; 1981.

52. Hwu JR, Lin YS, Josephrajan T, Hsu MH, Cheng FY, Yeh CS, et al. Targeted Paclitaxel by Conjugation to Iron Oxide and Gold Nanoparticles. J Am Chem Soc. 2009;131:66-8.

53. Mitova V, Hristova T, Cherkezova R, Koseva N, Yusa S, Troev K. Polyphosphoesterbased paclitaxel complexes. J Appl Polym Sci. 2015;132(45):42772-8. 